\title{
Helping our country as women scientists
}

\author{
Mayana Zatz is Professor of Genetics and Director of the Human Genome and Stem-Cell Research Center at the \\ University of São Paulo, Brazil. She works on neuromuscular disorders, ageing and, more recently, Zika virus and \\ cancer. She has a prolific publication record and is actively involved in ethical aspects of genetic research.
}

\section{Mayana Zatz}

S ince childhood I wanted to be a scientist. This was unusual, as most scientists then were men, but my parents, who emigrated from Europe to Brazil when I was 7 years old, always supported my choices. In high school I fell in love with genetics and studied biology to become a human geneticist. When Oswaldo Frota-Pessoa, one of the pioneers of human and medical genetics in Brazil, accepted me as a student in college, I started working with families with genetic disorders and became involved in genetic counselling. In this pre-DNA era few genetic tests were available and genetic counselling was largely based on risk estimates. One day, a young woman came to our lab. Her sister had three sons affected with Duchenne muscular dystrophy (DMD) and she was worried about her own risk of having affected children. We knew at that time that DMD affected mainly boys, but did not know about the risk of a female relative carrying the defective gene. Nobody was investigating this in Brazil and I wanted to help in some way. This was my first turning point. I established an enzymatic assay to measure serum creatine kinase and started studying families affected with muscular dystrophies.

After my BSc, I worked on my $\mathrm{PhD}$ studying 1000 people from families with muscular dystrophy. I also got married and had two children, Fabio and Cintia - undoubtedly my best experiment of recombinant DNA. It was not an easy time. I always felt guilty about not spending enough time either with my family, or in the lab. Doing research in Brazil, even today, can be hard. Importing reagents may take months and there is tremendous bureaucracy. But I never felt discrimination as a woman scientist. Today there are more women than men in biological sciences in Brazil. In universities, salaries are independent of gender and women can have six months maternity leave.

In 1975 we moved to the United States. It was a challenge, but I relished the opportunity to do my postdoc in a US lab. Under the supervision of Michael Kaback and David Rimoin at the University of California, Los Angeles, I continued working on enzymatic assays for muscular dystrophies. In the US, I felt gender inequality for the first time: men had higher

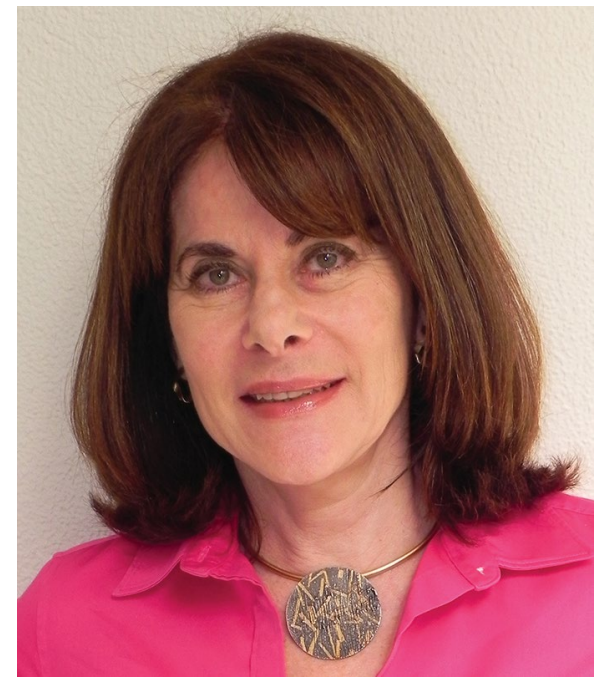

salaries, and women had no maternity leave. Although we could have stayed, I wished to do more for my country and returned to Brazil in 1977. I was shocked to find out that the patients I worked with previously had no support in their daily lives and founded the Brazilian Muscular Dystrophy Association, aiming to improve patients' quality of life my second turning point.

In the 1980s, my students, Maria Rita Passos-Bueno and Mariz Vainzof (now professors at our institute), and I introduced molecular biology into our lab. We mapped new neuromuscular dystrophy genes and focused on genotype-phenotype correlations. We observed wide clinical variability in patients carrying the same pathogenic mutation; while some were severely affected, others had mild, or no symptoms at all. Understanding their 'protective mechanisms' became our great interest, leading to 160 publications between 1990 and 2005. In 2000, I received a grant by FAPESP (the main funding agency in Brazil) to establish the Human Genome and Stem Cell Center- my third turning point. Under the center's aims of basic research, technology transfer and education, we sought to understand what underlies genetic variability and to identify new therapeutic targets. We studied the therapeutic effects of adult stem cells injected in neuromuscular animal models, derived induced pluripotent stem cell (iPSC) lines from patients with different mutations and studied golden retriever muscular dystrophy dogs, currently the best model for DMD. In 2008 , we started the ' 80 plus' project to generate a genome bank of elderly, healthy individuals from Brazil. Together with the Human Longevity Institute in San Diego, California, we performed whole genome sequencing of 1,320 individuals, the largest cohort in Latin America. Our analysis of 609 exomes revealed 200,000 previously unreported variants, highlighting the relevance of sequencing mixed populations, such as the Brazilian one. More recently I became interested in Zika congenital syndrome (ZCS). By generating iPSCderived neuroprogenitors from discordant ZCS dizygotic twins (one affected and one normal), and infecting them with Zika virus, we showed that ZCS depends on host genetic susceptibility. We also showed that Zika virus has potent oncolytic effects against xenografted human tumours of the embryonic central nervous system. If we translate these findings to humans, it will be the most important achievement of my career.

In 2001, I received the L'Oréal-UNESCO award for women in sciences. As the opposite of the stereotyped male scientist I had great visibility in the Brazilian media. I also became actively engaged in science policy and ethics, including in the approval by the Brazilian Congress of a bill allowing human embryonic stem cell research, which was ratified by the Supreme Court in 2008. My desire to help others by understanding human genetics and disease has guided my decisions to be a scientist, and to be involved with patients and science policy. I also try to convince students to embrace the enormous curiosity that drives them to science, because the life of a scientist is fascinating.

\section{Mayana Zatz \\ Department of Genetics and Evolutionary Biology, Human Genome and Stem-Cell Research Center, University of São Paulo, São Paulo, Brazil. e-mail:mayazatz@usp.br}

Published online: 28 August 2018 https://doi.org/10.1038/s41556-018-0161-9

Competing interests

The author declares no competing interests. 